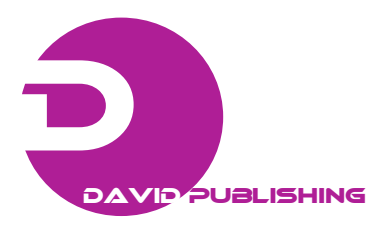

\title{
Animal Production Systems in Algeria: Transformation and Tendencies in the Sétif Area
}

\author{
Khaled Abbas \\ INRA Algeria, Unité de Sétif, Route des jardins, Sétif, 19000, Algéria
}

Received: July 13, 2012 / Published: October 20, 2012.

\begin{abstract}
Algeria registers only 0.25 ha of agricultural surface per capita. This indicates very low agricultural capacities. Otherwise agricultural activities are concentrated in a narrow fringe of the Northern part of the country where the dominant climate is semi-arid with very irregular rainfalls. A majority of farms produces its main part of income from cereal crops - livestock association system. However, the diversity of the climate and the physical environment, on one hand, and the agricultural policies on the other hand, induce major transformations in this system. Transformations are also the result of a significant demographic growth in rural area. In this context, significant issues appear in term of resource's uses and systems' sustainability. To shed light in the actual situation, this study, based on a survey of 90 owners, shows that: the intensification can constitute a threat on the pastoral resources; the weakness of the farms encourages the generalization of practices characterised by a weak feed autonomy and a bad management of stock fodders; the animal interspecific integration and partial intensification are positive if they follow models which ensure autonomy, performance and optimal pastoral resource management.
\end{abstract}

Key words: Algeria, semi-arid, production system, transformation, animal production, dairy cattle.

\section{Introduction}

In terms of natural resources, Algeria has an agricultural sector of multiple constraints.

Reduced agricultural surface relatively to total area and population number. Only a narrow fringe situated in the North of Algeria is not a desert area. It is about $1200 \mathrm{~km}$ long from East to West and 200 to $350 \mathrm{~km}$ large and is inhabited by more than 24 million people, which represents $70 \%$ of the total population.

Soils are mainly of low depth and terrain is often hilly: agricultural surfaces contains few plains. Hilly terrain provides also good conditions to erosion.

In this context, agricultural activities, mainly rainfall-related, have to take into account the preservation of the environment. It is worthy to note that for these reasons, agriculture in Algeria is farmer/livestock breeder and nomads' ones.

Corresponding author: Khaled Abbas, Ph.D., senior researcher, research field: animal production system improvement. E-mail: abbaskhal@yahoo.fr.
Furthermore, development of agriculture has always faced physical and climatic constraints.

A very binding climate and a scare water resources: the small coastal areas are characterised by absolute summer drought, winter concentrated rainfalls and mild and not very contrasted temperatures. The climate becomes harsh when we go away from the sea, especially, the decrease of the global rainfall. Major rivers flow is very irregular but without being intermittent [1].

After 1962 (independence year), the different policies' objectives regarding the rural development were focused on land use conservation (fighting against desertification in the literal sense), job's development in rural areas where there is no perspectives, and finally, increasing the national production in terms of food security [2]. However, rural and agricultural areas which were considered as simple stand to production and trade exchanges, have always been taken at a secondary level in the analysis 
and organisation of agricultural and agribusiness activities. Nowadays, the agricultural objectives are reassessed, local lands, areas, agricultural and rural spaces are seen in the middle of the society's expectations for providing a good quality of products and environment's protection. In Algeria, the granting of benefits of the agricultural development, in the frame of the different agricultural policies, has always been suffering from a lack of awareness of the agricultural diversity. In the semi-arid agricultural areas, desertification fighting, biodiversity and environment preservation give to agricultural development a strategic and primordial aspect [2].

The National Plan of Agricultural Development (2000) then Economic, Agricultural and Rural Renewal Policy (2006), are based on the establishment of specific tools for the development of different production's systems and rely on the agricultures strategies [3].

Scientific attendants of the application of the agricultural policies are aiming an optimal definition of the agricultural biodiversity in order to provide objective elements for the adjustment and the success of the different committed programs [3].

Aware that the stakes for survival and development of agriculture are mainly at the level of dynamics of:

Production Systems at farm level, agro-pastoral and pastoral areas whose role is felt in terms of ecological and renewable food resource, and aiming to target a clear view of the situation at these points of view we choose an approach of multilevel diagnosis.

The definition of the diversity of agricultural space at regional and local scales allows a target diagnosis of production systems. Structures and paths of evolution and strategies of production have to be accurate before any intervention. In fact, it is possible to identify through the finding of orientations and global tendencies, the "agro-zones" and the mapping of agricultural space in order to know the first indicators and global characteristics of production's systems at scales including entities of agricultural spaces [4-6].
Starting from this point, the diagnosis analysis work is structured in three levels of perception: national, regional and zonal in order to comprehend the tendencies and trajectories of the production's systems with integrating the dimension of the effects on the territory and spaces.

This communication is therefore divided into three parts: location of national agricultural spaces geared to cereal growing, identification of agricultural areas of the wilaya (department) of Sétif showing a definite cereal growing agricultural space, and finally, typology of agro-pastoral system at the scale of farms in the same area.

\section{Materials and Methods}

\subsection{Presentation of the Site of Study}

\subsubsection{Natural Characteristics}

Sétif is a wilaya (department) situated in the Northeast of Algeria. It represents an agro-ecological zone called "the high cereal plains" with a height which often exceeds $1,000 \mathrm{~m}$. The zone of Sétif is a representative example of the Mediterranean regions with rainfed cereal crops associated with livestock (mainly sheep).

The weak cereal yields in this region were always awarded to the aridity of the climate. Indeed, this one is characterized by a low annual rainfall and especially a very irregular inter-annual seasonal distribution. The rainfall is very low (250 in $300 \mathrm{~mm}$ ) in South zone of Sétif region to become relatively more important in North zone with maximums of $400 \mathrm{~mm}$. Altitude and climate of Mediterranean type impose a very cold and rainy winter, associated with relatively dry spring which is characterized by late gel. The summer is very dry and hot prohibiting any crop without irrigation. The winter cold limits the growth when water is available and lengthens the cycle of the plant to expose it to the stress at the beginning of the summer.

The Northern zone with reduced surfaces comprises soils not or little calcareous, black and argillaceous. The Southern zone containing more significant surfaces 
possesses calcareous soils with hard calcareous accumulations close to the surface [1]. The intensive ploughing is one of the paramount factors of continuous degradation of soils by its impoverishment out of organic matter and its exposure to water erosion [1].

The area of Sétif is effectively located at a zone of strong impoverishment of the soil (Fig. 1). If the relief is relatively flat on soils with low depth and calcareous encrusting, the North and South zones are very corrugated and very favourable to water erosion.

\subsubsection{Agricultural Characteristics}

In addition to the preceding natural constraints, the socio-economic factors are unfavourable, in particular, concerning the atomization of the production structures with a high proportion of farms having a weak UAA (Fig. 2).

The cereal crops occupy the most important share of the UAA and constitute the dominant crop of nearly the total of the municipalities of the Wilaya (Fig. 3). The average yield in rainfed crop is weak, which is about 5-6 q/ha [7].

Like the cultivation of cereals, the sheep agropastoral farming system is very frequent and is held by the large majority of the farms. It is practised

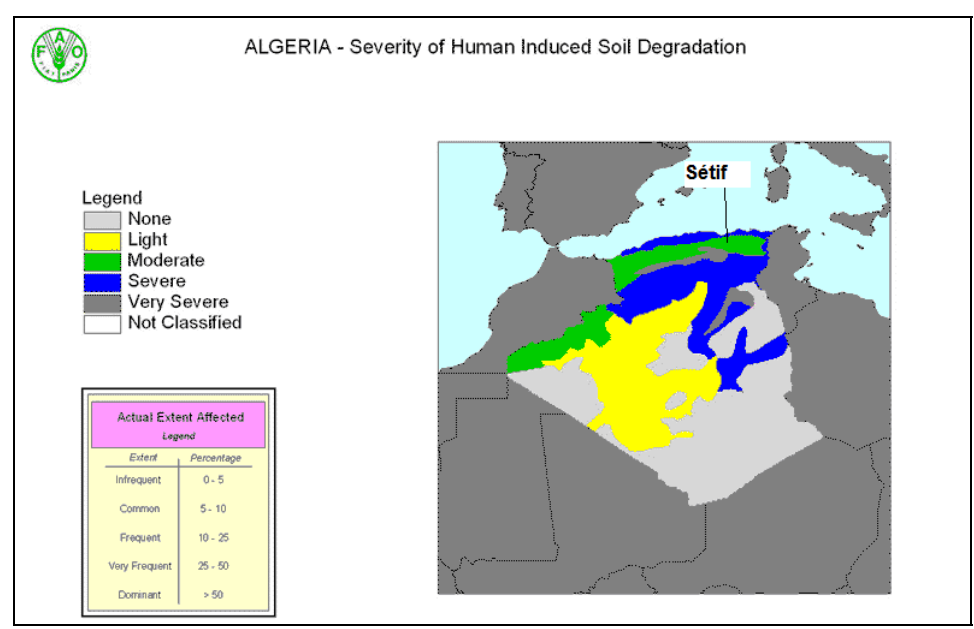

Fig. 1 Severity of the impoverishment of the soil under the effect of the human activities in Alegria (FAO).

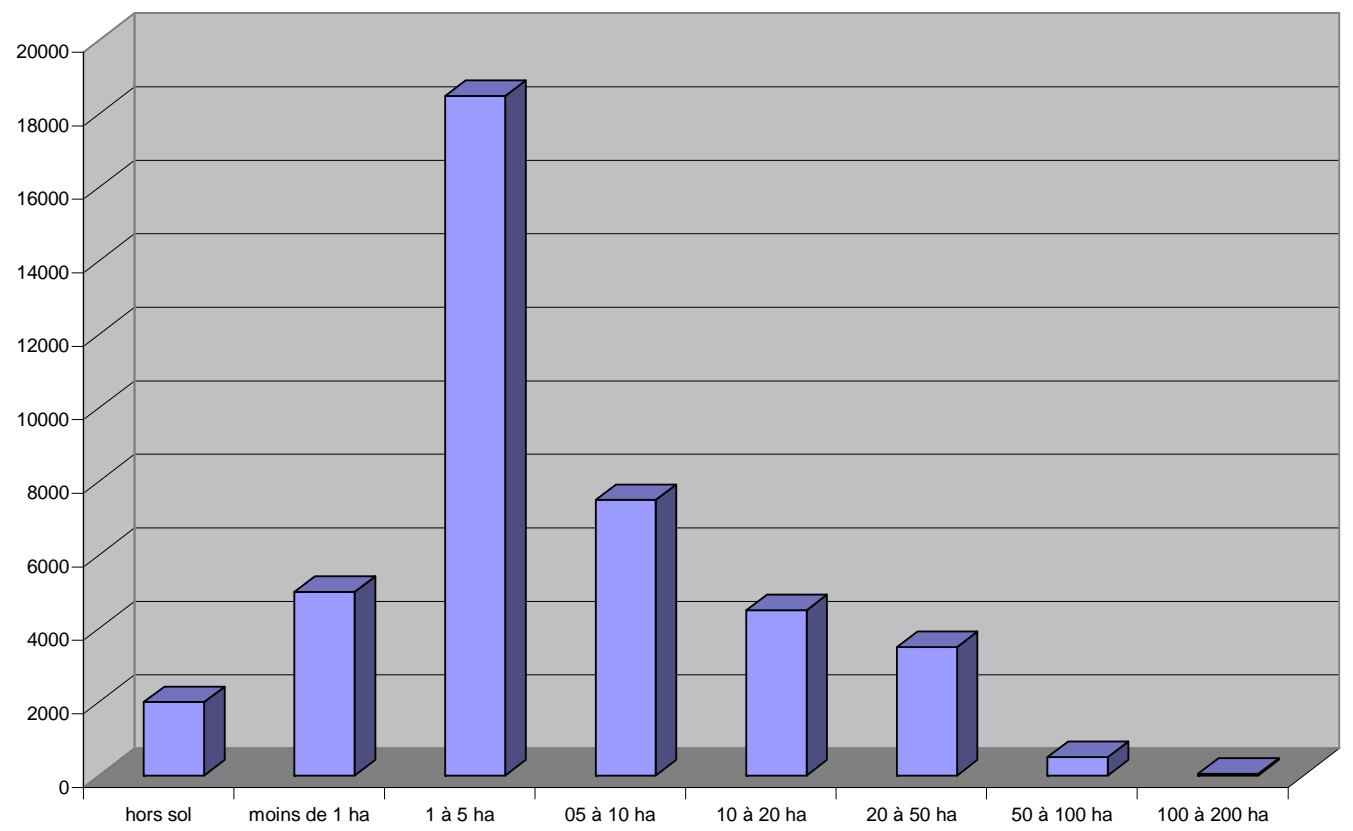

Fig. 2 Distribution of the farms of the wilaya of Sétif according to the size of the UAA in ha (DSA of Sétif, 2004). 


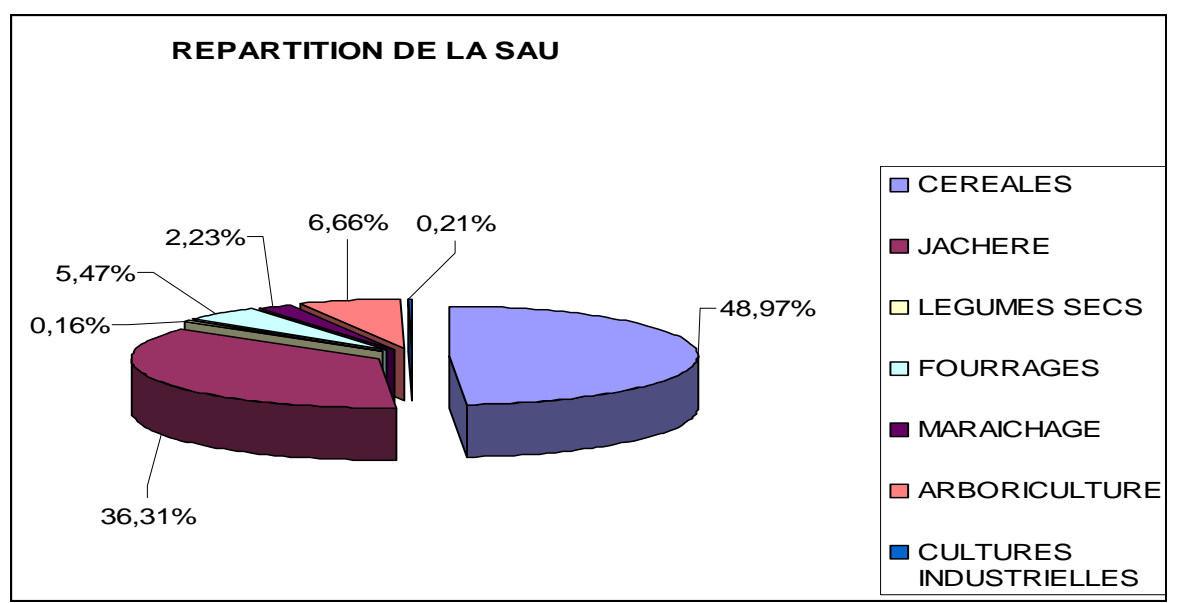

Fig. 3 Average distribution of the UAA in the wilaya of Sétif.

on the fallow and the residues of crops. With the sheep farming, and in spite of the weakness of the fodder resources, the dual purpose cattle breeding (meat-milk) is also very frequent. The livestock farming constitutes an integral share of the production systems for which it represents the first source of incomes (Benyoucef et al., 2000). It represents also a very significant factor of securization for these systems against the risk of drought with which are confronted the rainfed crops.

\subsection{Data Sources}

Three types of data were used:

For the study of the diversity of national cereal space, the location of diversity is made on the basis of official statistics on the scale of the wilaya (department). These statistics were projected on geographical and natural maps.

Concerning the study of the agricultural diversity of the wilaya of Sétif, the decennial averages of the statistics of the Ministry for Agriculture on a communal scale were used.

The typology of the production systems of the wilaya of Sétif was built on the basis of exhaustive survey of closed type carried out on a sample of 90 farms randomly chosen in 4 communes. The survey was related to:

- The land capital

- Useful agricultural area (UAA)

- Irrigated surface
- Characteristics of the livestock

- Number and structure of the exploited livestock

- Breeds

- Equipment of breeding (standard of cattle shed and mode of housing)

- The management of the herds

- Feeding practices

The place of survey (Fig. 4) is on two micro-areas of the wilaya of Sétif located beforehand by the study of regional diversity (cereals-sheep farming and cereal-sheep and dairy cattle farming). These two small semi-arid zones correspond respectively inferior (200-300 mm) and superior (300-400 mm), in order to apprehend the range of strategies of the actors in more or less constraining medium.

\subsection{Statistical Methods}

In the study of regional diversity, some data were used without preliminary transformations; it is UAA, surface of wheat, barley, grazed fallow, ploughed fallow, mown fallow, rangelands (except UAA), number of ewe, cows and goats. The other data were transformed to lead to the following indicators:

"Principal fodder surfaces": grazed and mown fallows, fodder crops and meadows.

"Cereal surface": cereals and ploughed fallow (regarded as lands taken from breeding and used for cereals). "Corrected manpower of ewe": calculated to exclusively bring it closer to specific pastoral surfaces 


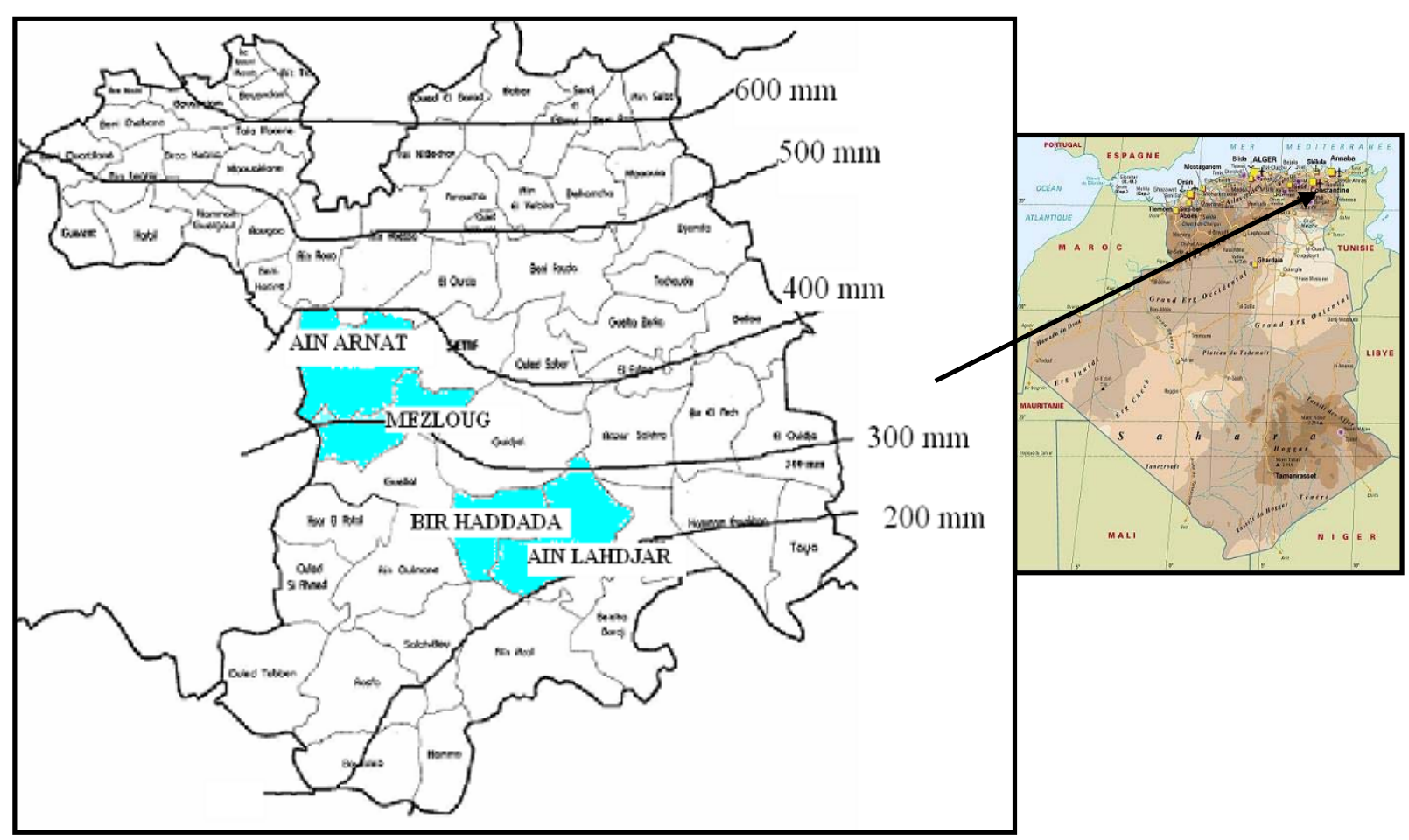

Fig. 4 Positioning of the communes covered by the survey in the climatic agro space of the wilaya of Sétif.

to the farms without over-estimate induced by the means as of manpower living on rangeland (out of UAA):

Corrected manpower of the ewes $=$ ewes number (effective ewe $\times$ rangeland/(rangeland + UAA)) .

These data were used for the development of a correlation matrix aiming to gather the criteria explaining the most variability and of interpreting their contents by the definition of dominant agricultural orientations. The data of the investigation were organized in the form of two-dimensional spreadsheet containing, in lines, the farms and, in columns, the various variables. The variables made possible to study the main features of the production units per calculation of descriptive statistics. A typology of the production systems was made by multivariate analysis. A PCA on quantitative informations, then a CFA on qualitative data and quantitative information transformed in classes made possible to identify the discriminating variables. Using an Ascending Hierarchical clustering (AHC), the farms were then classified in order to analyze the consequences of the variability of the production systems on the operating system and on the variability of the animal farming. The software used is Excel.7 and XLStat.7.

\section{Results and Discussion}

3.1 Study of the Diversity of the Agricultural Space of the Cereal Zones on a National Scale

The study of space diversity on national level shows that the wilaya of Sétif belongs to under area including several wilayas and characterized by the cultivation of cereals like mining crop but also supplemented by other agricultural speculations (Fig. 5). This shows that the diversification of the agricultural activities constitutes an orientation witch appear on a global scale and represents thus a heavy tendency.

3.2 Study of the Diversity of the Agricultural Space of the Wilaya of Sétif: Five Small Agricultural Areas

The interaction between the climate, the relief and the physical environment make that Sétif has a strong diversity. The identification and the characterization of 


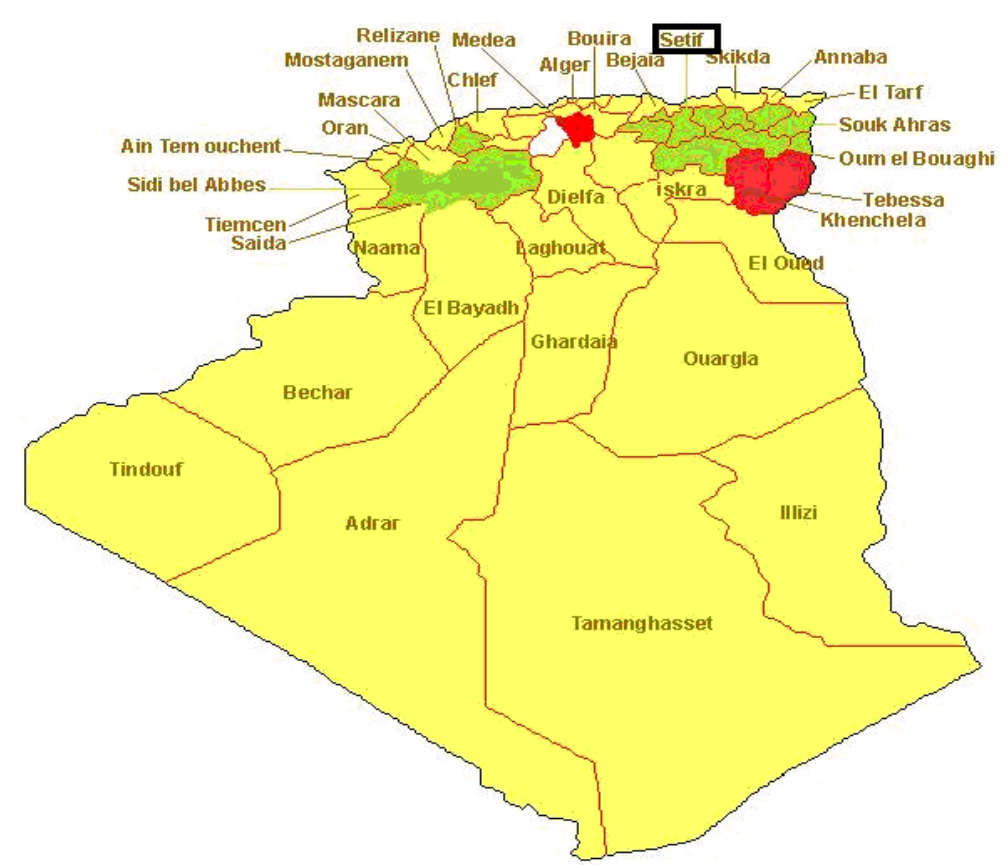

Fig. 5 The three variants of Wilayas within the cereal zone.

Legend:

\begin{tabular}{l|l} 
Cereals and other crops & Dominant cereals
\end{tabular}

Cereals and pastoralisme

this diversity must allow a better approach of the regional development by the target of agro-areas and dynamic of production. This work was thus completed while following the following stages:

a Delimitation of the cereal territory

As our study is focused on the agricultural territory dominated by agrgropastoralism (cereals-livestock farming), we eliminated from our investigation the communes located at the North ends and south of the wilaya. These zones are specific mountainous (agroforestery). The territory remaining is overall with cereal predominance.

b Diversity of space with cereal predominance

The analysis of the correlations and the classification of the criteria of the communes of the cereal zone in the wilaya of Sétif emphasize 4 orientations (Fig. 6):

Cereal crops-sheep farming;

Cereal crops-sheep farming with rangelands, goat and orcharding;

Cereal crops-sheep farming with truck farming and dairy cattle;
Cereal crops-sheep farming with dairy cattle;

In orientation 1 , the rainfed and extensive cereals is associated with sheep herds which reduce the risks of climate/soil uncertainties. The irregularity of rainfall and the low depth of the soil are indeed the principal constraints of this zone. Orientation 2 is located on the edges of mountain. The farms associate the cereal and pastoral practices with sylviculture and arboriculture dimensions. Orientation 3 is located at the North-West, the center and South-West. It follows geographically the effluents of the Boussellam River which constitutes the most significant river. It concerns also bottomland of the central area of El Eulma. The availability of underground water resources explains the orientation of this area. Orientation 4 relates to offset area compared to the preceding one (in North and the South) and is characterized by more important bovine slag.

\subsection{Study of the Diversity of the Farms}

\subsubsection{Principal Components Analysis (PCA)}

On a file of 27 variables and 90 farms, this analysis 


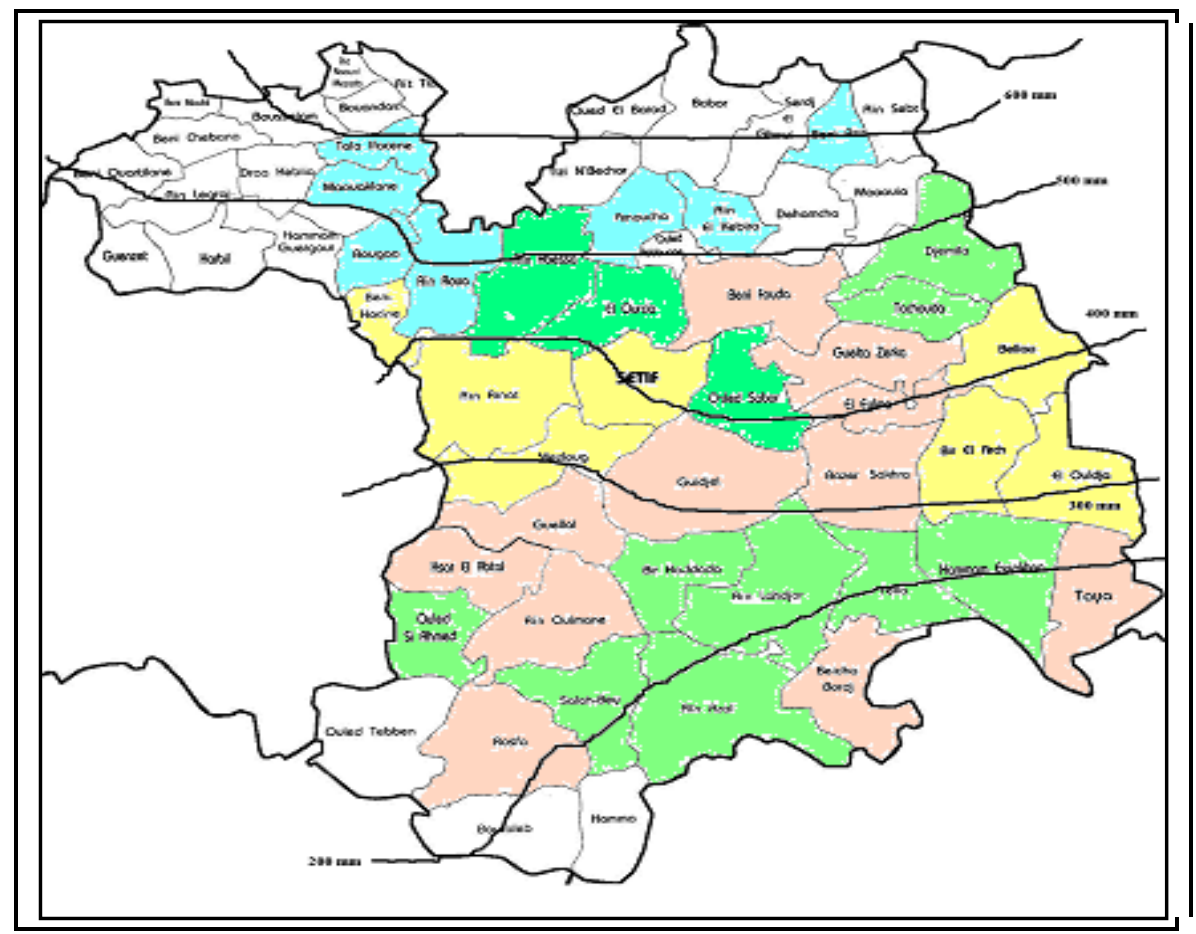

Fig. 6 Typology of the communes of the cereal zone of the high plains area of Sétif.

\section{Legend:}

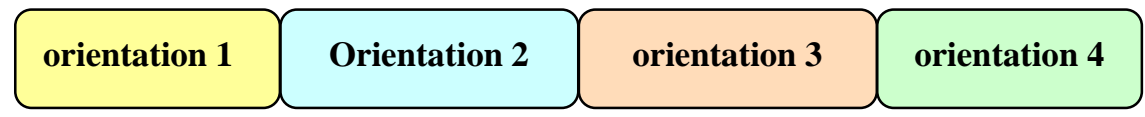

made possible to gather $70 \%$ of total inertia on 5 axes including $55 \%$ for the first three. The latter discriminate the farms studied according to:

Size (SAU, total «Livestock Unit» (UGB), cereal surface...etc.) (35\%);

Importance of the irrigated surfaces (20\%);

Composition of the total UGB (bovine UGB; ovine and goat) (15\%);

The PCA highlighted factors of dimension of the farm and composition of the livestock.

\subsubsection{Correspondences Factor Analysis (CFA)}

The CFA gathered $63 \%$ of total inertia on 5 axes, including $48 \%$ for the 3 first ones. These axes are defined by the following variables:

The irrigated surfaces opposed to the fattening of sheep and the use of rangeland: strategies of animal or vegetal intensification (22\%);

The irrigated fodder surfaces in opposition to the irrigated green barley and the quantity of concentrate ewe: the degree of fodder intensification versus concentrate feeding autonomy (16\%);

The surfaces of market gardening under greenhouses: the strategies of intensification in gardening coupled with the water economy (10\%);

This analysis highlights the diversity of the strategies of assignments of the irrigated surfaces by the taking into account or not of the livestock.

\subsubsection{Hierarchical Ascendent Clustering (HAC)}

This method allows highlighting 5 groups of farms (Fig. 7).

Table 1 summarizes the principal characteristics of the identified 5 groups of farms.

3.3.4 Description of the Groups of Exploitations

Group 1 is composed of farms of very small size (7.5 ha, 3 UGB) and concerns more than $11 \%$ of the sample. Groups 2, 3 and 4 have a near average SAU (between 12 and 20 ha) and livestock of variable size and composition (between 6 and 14 UGB). These three groups contain approximately $80 \%$ of the surveyed exploitations. Their structures can be qualified reduced 


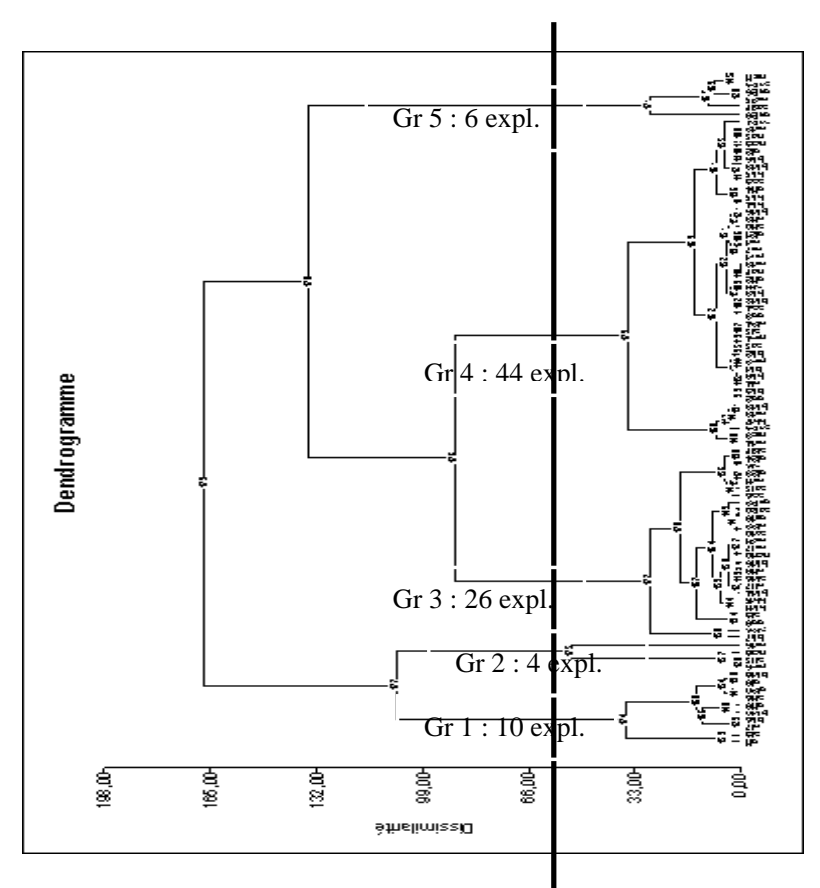

Fig. 7 Description of the main groups of farms using the dendrogram of the HAC.

dimensions, considering the extensive and rain character of agriculture in semi-arid zone. Group 5 is different, on the other hand, from the other groups by structural parameters (SAU, total UGB) definitely more significant (148 ha, 21.2 UGB) but it gathers only 7\% of the sample. These structures can be qualified of reduced dimensions, considering the extensive and rainy character of agriculture in semi-arid zone. These last three groups represent approximately $80 \%$ of the surveyed farms. The results of the last RGA (general census of agriculture, MADR, 2001) put forward the importance of the phenomenon of atomization of the farms in Algeria and in the wilaya of Sétif. The sample, randomly selected shows thus clearly a situation embrittlement concerning a significant part of production units.

Preceding work [8, 9] released a phenomenon of fragmentation of the farm's size associated with a strong pastoral tendency on unstable bases (lack of UAA, pastures on rented surfaces.). This report is coupled with a tendency of diversification, in particular at the farms of lower size. That made re-appear the general problem of the arable lands (parcelling-out and joint-possession of the private property, instability of the statute of the public property, disorganization of arable lands market...). The tendency to reducing the structure size of the production systems and the parcelling-out of the UAA mark beginnings of a disturbance of the practices of access and use of the pastoral areas. These last allowed the maintenance of large herds by the owners what armed them more to fight climatic hazards on cereal harvests, thus fitting in a prospect of sustainability [10]. The variability of the studied sample can be organized according to the tree structure presented on Fig. 8.

Besides the general observations on the reduction of structures and diversification, it appears that farms adopt different strategies. Those are based on the intensification of the use of agricultural surfaces by the practice of fodder crops and of the truck farming particularly at those of very small size. At the medium size farms (12 to 20 ha), a very small fringe (4\%) seems to move away from the major diagram of sheep are represented by the "cereals-dairy cattle" and the “cereals-pastoralism”. The latter is probably less stable than that found at the large farms, since it is practiced

Table 1 Average surfaces of the main crops (ha) and livestock (UGB) of the 5 groups of farms (in bolt principal characteristics of each group).

\begin{tabular}{|c|c|c|c|c|c|c|c|c|c|c|c|c|}
\hline Group & Number & Total \% & UAA & $\begin{array}{l}\text { Irrigated } \\
\text { UAA/ } \\
\text { total } \\
\text { UAA } \\
\end{array}$ & $\begin{array}{l}\text { Cereal } \\
\text { Surface/ } \\
\text { UAA }\end{array}$ & $\begin{array}{l}\text { Principal } \\
\text { Fodder } \\
\text { Surface/ } \\
\text { UAA } \\
\end{array}$ & $\begin{array}{l}\text { Fodder irrigated } \\
\text { Surface } \\
\text { /principal fodder } \\
\text { surface }\end{array}$ & $\begin{array}{l}\text { Total } \\
\text { UGB }\end{array}$ & $\begin{array}{l}\text { Total } \\
\text { UGB/SA } \\
\text { U }\end{array}$ & $\begin{array}{l}\text { Sheep } \\
\text { UGB/ } \\
\text { Total } \\
\text { UGB }\end{array}$ & $\begin{array}{l}\text { Cattle } \\
\text { UGB/ } \\
\text { Total } \\
\text { UGB }\end{array}$ & $\begin{array}{l}\text { Market } \\
\text { gardenin } \\
\text { g/SAU }\end{array}$ \\
\hline 1 & 10 & 11.11 & 7.53 & 0.08 & 0.62 & 0.15 & 0.85 & 2.85 & 0.38 & 0.57 & 0.43 & 0.03 \\
\hline 2 & 4 & 4.44 & 13.25 & 0.69 & 0.33 & 0.04 & 0.25 & 14.5 & 1.09 & 0.16 & 0.84 & 0.34 \\
\hline 3 & 26 & 28.89 & 19.46 & 0.05 & 0.67 & 0.10 & 0.02 & 6.09 & 0.31 & 0.27 & 0.63 & 0.02 \\
\hline 4 & 44 & 48.89 & 12.02 & 0.05 & 0.67 & 0.02 & 0.03 & 8.89 & 0.74 & 0.69 & 0.29 & 0.05 \\
\hline 5 & 6 & 6.67 & 148.08 & 0.03 & 0.59 & 0.05 & 0.00 & 21.2 & 0.14 & 0.56 & 0.44 & 0.01 \\
\hline
\end{tabular}




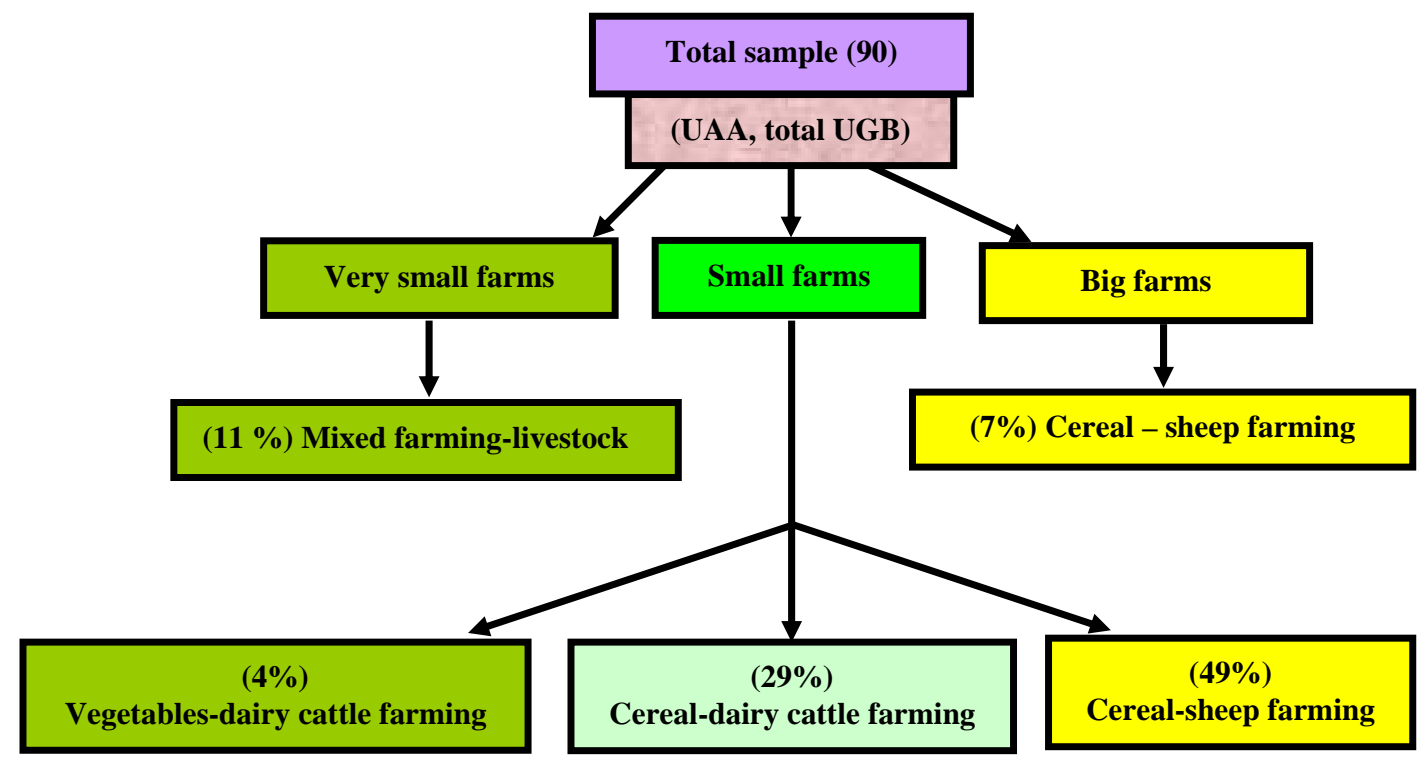

Fig. 8 Representation of the diversity of the production systems of the studied area.

out of UAA of the farm, which let us suppose a greater precariousness of access to the land. The sheep farming associated with cereal crops in the large farms represents $7 \%$ of surveyed farms.

Thus, it arises clearly that the reduction of the farm size is accompanied by strategies founded on the mobilization of water like the gardening or irrigated fodder crops. The cattle farming could integrate these strategies like a valorization module but it is sometimes conducted on zero grazing (dairy bovine without fodder). The form of ovine pastoralism associated with the cereals characterized by its anchoring history and its strong adaptation to the climatic, hydrous and edaphic conditions is thus driven back in the big sizes and autonomous farms on fallows and farms of less size with partial fodder autonomy (less grazed fallow) [11]. The last system meet more difficulty of reaching rangeland and fallow in location less and less available because of the transformation of the other systems towards least extensive forms (intensification of cereals causing less grazed fallow).

In this context, fundamental stakes appear on the use of the resources and the sustainability of the production systems. So we can admit, on the basis of preceding analysis that (i) the intensification can constitute a threat on the pastoral resources; (ii) the brittleness of the farms encourages the generalization of practices marking a weak feeding autonomy of the livestock and a bad fodder stock management (cereal straw, dry fodder but also grazed fallow) due to the unavailability and speculation between producers non-breeders and breeders and breeders non-producers; (iii) animal interspecific integration and the partial intensification could constitute positive ways if they follow models which ensure fodder autonomy, income guarantee and the optimal management of the pastoral resources (valorization of the fallow, creation and improvement of the meadows).

\section{Conclusions}

The semi-arid area of setifian high plains is confronted with a multitude of natural and socio-economic constraints. The analysis of the various strategies of the studied sample emphasizes great stakes on space, pastoral and hydric resources. These stakes are especially induced by the parceling-out of agricultural land. This situation returns necessary the search for models guaranteeing balance between the use of the resources and the viability of the farms. The role of agropastoral and natural spaces (natural fallow, meadows and rangelands) for this reason seems like factors of balance in the projects including the integration of dairy cattle. 


\section{References}

[1] R. Lahmar, Cereal intensification in Setif High Plains. Some results. Intensification céréalière dans Hautes Plaines Sétifiennes. Quelques résultats. Cahiers Options Méditerranennes, 2 (1993) 93-97.

[2] O. Bessaoud, Agriculture in Algeria from self managment to adjustment (1963-1992), L'agriculture en Algérie de l'autogestion à l'ajustement (1963-1992), Options Méditerranéennes, 8 (1994) 89-103

[3] O. Bessaoud, The rural development strategy in Algeria. La stratégie de développement rural en Algérie, Options Méditerranéennes, 71 (2006) 79-89.

[4] 14) M.T. Benyoucef, T. Madani, K. Abbas, Farming systems and breeding objectives in sheep living in semi-arid Algerian. Systèmes d'élevage et objectifs de sélection chez les ovins en situation semi-aride algérienne, Options Méditerranéennes, 43 (2000) 101-109.

[5] Chambres d'Agriculture, The value of agricultural zoning. L'intérêt d'un zonage agronomique, 719 (supplement) 1985, Chambres d'agriculture, France.

[6] INRA Maroc, Applicability of participatory SWOT tool for self-evaluation actions pastoral development in Eastern Morocco Applicabilité de l'outil participatif SEPO pour l'auto-évaluation des actions d'aménagement pastoral au Maroc oriental. Ouvrage collectif, INRA Maroc, 1995, p. 65.
[7] R. Ambroise, M. Barnaud, G. Vedel, D. Legros, A new path in agriculture: The development plans. Une voie nouvelle en agriculture: les plans de développement. Aménagement et nature, 117 (1995) 7-14.

[8] M. Kribaa, S. Hallaire, J. Curmi, Effects of tillage methods on soil hydraulic conductivity and durum wheat grain yield in semi-arid area, Soil and Tillage 37 (2001) 17-28.

[9] K. Abbas, T. Madani, E H. Bencheikh, L. Merraouche. Sheep production systems in semi arid cereal: farm size and pastoral character, Systèmes d'élevage ovin en zone semi aride céréalière: taille d'exploitation et caractère pastoral, New Médit., 1 (2002) 50-55.

[10] K. Abbas, T. Madani, Spatial diversity and natural in Wilaya de Sétif. implications on the direction of agricultural activities. La diversité spatiale et naturelle dans la Wilaya de Sétif. implications sur l'orientation des activités agricoles. Rapport de travail, INRAA/CRSTRA, (2002)

[11] J. Pluvinage, Production systems cereal-livestock and risk management in dryland Mediterranean. Les systèmes de production céréales-élevage et la gestion du risque dans les zones sèches méditerranéennes. Thèse de doctorat en Sciences économiques, INRA-ENSAM (1995)

[12] K. Abbas, M. Abdelguerfi-Laouar, T. Madani, A. Mebarkia, A. Abdelguerfi, Role and use of natural grassland in semi-arid altitude in Algeria. Rôle et usage des prairies naturelles en zone semi-aride d'altitude en Algérie. Fourrages, 183 (2005) 475-479. 